\title{
Competitive flow in coronary bypass surgery: The roles of fractional flow reserve and arterial graft configuration
}

\author{
From the a Faculty of Medicine, University of Sydney, The Baird Institute of Applied Heart \& Lung Surgical \\ Research, Sydney, New South Wales, Australia; and ${ }^{b}$ Department of Cardiovascular Surgery, John Radcliffe \\ Hospital, Nuffield Department of Surgical Sciences, University of Oxford, Oxford, United Kingdom. \\ Received for publication March 22, 2017; revisions received May 4, 2017; accepted for publication May 29, 2017; \\ available ahead of print June 23, 2017. \\ Address for reprints: Hugh S. Paterson, FRACS, The Baird Institute, 305/100 Carillon Ave, Newtown, New South \\ Wales 2042, Australia (E-mail: patersonh@aol.com). \\ J Thorac Cardiovasc Surg 2017;154:1570-5 \\ $0022-5223 / \$ 36.00$ \\ Copyright $(2) 2017$ by The American Association for Thoracic Surgery \\ http://dx.doi.org/10.1016/j.jtcvs.2017.05.087
}

Hugh S. Paterson, FRACS, ${ }^{a}$ Paul G. Bannon, PhD, FRACS, ${ }^{a}$ and David P. Taggart, MD, PhD, FRCS ${ }^{b}$

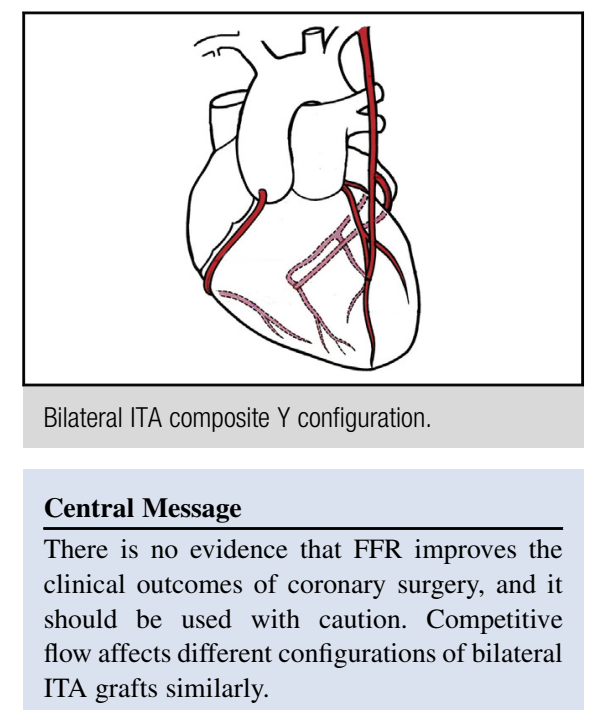

Competitive flow reduces the patency of arterial grafts after coronary bypass surgery. Competitive flow is dynamic, relative, and to a certain extent unavoidable. The preoperative assessment of the severity of coronary stenoses and the prediction of competitive flow can be improved by the addition of fractional flow reserve (FFR) measurements to coronary angiography, but the potential for mitigation of the effects of competitive flow by different graft configurations appears limited. Evidence relating to assessment by FFR and management by selective graft configuration will be reviewed separately as follows.

\section{FRACTIONAL FLOW RESERVE}

\section{The Principle of Fractional Flow Reserve}

FFR is the ratio of pressure measurements in the poststenotic section of a coronary artery and in the ascending aorta at maximal coronary vascular pharmacologic dilatation. A decrease in the coronary artery pressure relative to the aortic pressure in association with a decrease in vascular resistance in the coronary arteriolar system implies a restriction of the increase in flow that would normally occur during a period of low vascular resistance. A coronary artery pressure to aortic pressure ratio of less than 0.8 implies a significant coronary artery stenosis. As flow is proportional to pressure, this pressure ratio is termed "fractional flow reserve" and is the physiologic or functional estimate of a coronary artery stenosis. Unfortunately, there is no calculation that can convert an FFR estimate of stenosis to equate to an anatomic (angiographic) estimate, but correlations have been developed from observation. The Fractional Flow Reserve versus Angiography for Multivessel Evaluation (FAME) trial showed that for angiographic stenoses greater than $90 \%$, FFR was negative (ratio $>0.8$ ) in $4 \%$ of patients; for stenoses $71 \%$ to $90 \%$, FFR was negative

See Editorial Commentary page 1576. in $20 \%$ of patients; and for stenoses $51 \%$ to $70 \%$, FFR was negative in $65 \%$ of patients. ${ }^{1}$ FFR for percutaneous coronary intervention (PCI) tested the hazard of unnecessary stent deployment (false-positive angiogram) against the hazard of failure to deploy appropriately (false-negative FFR). Although the occurrence of a false-positive angiogram carries the greater hazard, it does not mean that a false-negative FFR is without hazard. These hazards are specific for deployment of drug-eluting stents in the prescribed clinical situation. The false-negative rate for FFR has been estimated at $12 \%$ in a small trial $(n=24)$ when tested against the combination of stress testing for evidence of myocardial ischemia and a positive angiogram. ${ }^{2}$ The FFR false-positive rate appears irrelevant and cannot be determined when only tested against angiographically positive stenoses, but has been estimated at $8 \%$ in one small study $(n=62)$ of nonstenotic coronary artery disease, ${ }^{3}$ and although not quantified in the DEFER trial, appeared to be significant, possibly contributing to adverse outcomes in the reference group $^{4}(n=325)$.

\section{The Role of Fractional Flow Reserve in Coronary Artery Stenting (Percutaneous Coronary Intervention)}

FFR was introduced approximately 20 years $\mathrm{ago}^{2}$ and proved its value in the Fractional Flow Reserve versus Angiography for Multivessel Evaluation randomized trial $(n=1005)$ of angiography plus FFR versus angiography 
alone for guidance of stent deployment in multivessel disease. The addition of FFR to guide stenting of coronary artery stenoses reduced the number of stents deployed by $30 \%$ relative to guidance by angiographic assessment alone, with an associated decrease in the combined outcome of death, myocardial infarction, and repeat revascularization. ${ }^{1}$ The difference in event rates occurred in the first 14 days after PCI, but subsequently, the event rates in each group were almost identical over the ensuing 5 years so that the initial statistically significant difference was lost in the subsequent larger numbers of events. ${ }^{5}$

There is some concern that the use of FFR will likely downgrade some stenoses from visually significant to functionally insignificant with the result that some patients who would normally be recommended for coronary artery bypass grafting $(\mathrm{CABG})$ for survival benefit will no longer receive that recommendation. Although this may be superficially logical, it lacks supporting evidence. Indeed, the recent FUnctional Testing Underlying Coronary REvascularization randomised trial (angiography + FFR vs angiography only guided management of multivessel disease including the left anterior descending) $(\mathrm{n}=936)$ was terminated prematurely because of increased mortality in the FFR arm. ${ }^{6}$ Of note, the excess mortality was predominantly in the PCI cases in that arm. Although detailed analysis of data is not yet available, it will be particularly important for the investigators to demonstrate whether the excess mortality was due to changing interventional options from CABG to PCI after FFR.

\section{The Role of Fractional Flow Reserve in Coronary Surgery}

In the only published trial of FFR before coronary surgery with subsequent angiographic follow-up $(n=153)$, the surgeons were blinded to the findings of preoperative FFR. This trial demonstrated that occlusion of grafts to arteries with angiographically (anatomically) significant but FFR (physiologically) insignificant stenosis resulted in insignificant morbidity. Furthermore and somewhat surprisingly, graft closure due to competitive flow was equally apparent for both vein and arterial grafts. ${ }^{7}$ However, this trial was not designed to assess the safety of FFR-guided coronary surgery or sufficiently powered to confirm the safety of graft occlusion to arteries with nonphysiologic stenoses. In a separate retrospective observational study of FFR-guided coronary surgery, there were fewer coronary anastomoses and a lower incidence of subsequent angina in the FFR group $(n=198)$ versus the angiogram only group $(\mathrm{n}=429)$, but an important limitation was a failure to establish the effect of the use of FFR to change the interventional strategy from CABG to PCI. ${ }^{8}$ As such, there is little evidence supporting the use of FFR for coronary surgery. Intuitively, FFR might improve coronary bypass graft patency rates by reducing the incidence of the deleterious effects of competitive flow on arterial grafts, but the extent of the potential clinical benefit from the avoidance of graft occlusion due to competitive flow is unknown. Whereas the unnecessary deployment of stents to coronary arteries without significant stenoses has been definitively shown to increase patient morbidity, the deployment of additional coronary bypass grafts to arteries without significant disease appears to carry minimal morbidity. Although the occlusion of an unnecessary stent causes occlusion of a high-flow coronary artery with potentially devastating clinical impact, the closure of an unnecessary bypass graft has little impact on coronary flow or subsequent clinical outcome.

As clearly demonstrated in the TAXUS Drug-Eluting Stent versus Coronary Artery Bypass Surgery for the Treatment of Narrowed Arteries (SYNTAX) trial, ${ }^{9}$ the evidence for the survival benefit provided by coronary surgery is based on the visual angiographic rather than the functional FFR assessment of coronary artery stenoses. Consequently, it is reasonable to suggest that the survival benefit of CABG is driven by grafts to coronary arteries with both anatomically and physiologically significant stenosis and not by those without both, but this is yet to be proven. It is important to understand the evidence on which a recommendation for survival benefit for CABG can be made. ${ }^{10}$ The randomized trials of coronary surgery versus medical therapy that commenced during the 1970 s provided data on which recommendations have been based for many years. The Coronary Artery Surgery Study $(\mathrm{n}=780)$ used a $70 \%$ or greater anatomic stenosis in a major artery in each system as the definition of triple-vessel disease, but this did not provide a survival benefit over medical therapy unless it was in conjunction with another risk factor, such as left ventricular impairment, stenosis in the proximal left anterior descending artery, a strongly positive stress test, or Canadian class symptoms greater than $2 .{ }^{11}$ The other trials conducted at that time used a $50 \%$ or greater coronary stenosis for trial entry, but a subgroup analysis to determine the significance of moderate stenoses $(50 \%-70 \%)$ was not performed. ${ }^{12}$ The findings of the SYNTAX trial $(n=1800)$ (coronary surgery vs PCI for triple-vessel disease or left main coronary artery stenosis) also were based on anatomic assessment of the coronary stenoses, and the SYNTAX score required for a survival benefit from coronary surgery relative to drug-eluting stent deployment was remarkably consistent with recommendations based on the trials of the 1970s. ${ }^{9,13}$ These findings are consistent with data from the New York State ${ }^{14}$ and Duke University ${ }^{15}$ registries. The hazard of grafting vessels with insignificant stenoses appears small, but failure to graft major vessels with a stenosis greater than $50 \%$ at the time of surgery is associated with reduced survival, ${ }^{16}$ and a survival benefit for internal thoracic artery (ITA) grafts to the subset of coronary arteries with moderate stenoses has been demonstrated. ${ }^{17}$ The intraoperative decision making for survival benefit (stenosis 
$\geq 50 \%$ ) differs from the preoperative decision making (stenosis $\geq 70 \%$ ). This among other factors has contributed to confusion regarding the definition of prognostically significant coronary stenoses.

In summary, (1) FFR has proven benefit in guiding PCI, but there is insufficient evidence to determine that FFR improves clinical outcomes of coronary surgery; (2) FFR is not a stand-alone investigation and primarily is used to improve the angiographic assessment; and (3) FFR is likely to be of benefit in the assessment of angiographically equivocal stenoses before coronary bypass surgery.

\section{ARTERIAL GRAFT CONFIGURATION}

For patients undergoing coronary bypass surgery in whom moderate stenoses are likely to be associated with competitive flow, the management choices are to graft or not to graft, to modify the selection of the bypass conduit, or to modify the bypass graft configuration. Tatoulis and colleagues ${ }^{18}$ have demonstrated an increased sensitivity of the radial artery to the effects of competitive flow resulting in an increased incidence of graft occlusion relative to that of ITAs. The extent of the sensitivity of the radial and gastroepiploic arteries has not been quantified or studied as extensively as that for ITAs for which a variety of bypass configurations have been studied.

There has been 1 randomized trial and several observational comparative studies with long-term clinical followup comparing bilateral ITA in situ grafts with a bilateral ITA composite $\mathrm{Y}$ graft configuration (free right ITA joined to the side of the left ITA). The randomized trial $(n=304)$ showed no difference in graft patency rates at elective angiography 6 months postoperatively ${ }^{19}$ but a benefit for the $\mathrm{Y}$ graft configuration in reducing the combined outcome of death, myocardial infarction, revascularization, and stroke at 7 years. There was no difference in survival, ${ }^{20}$ but the benefit for the composite outcome was driven by a lower rate of repeat revascularization in non-ITA-grafted territories reflecting the wider territory of ITA myocardial revascularization in the $\mathrm{Y}$ graft group (due to the greater number of distal ITA anastomoses, 3.2 vs 2.4 per patient) rather than improved graft patency. The observational studies (total $\mathrm{n}=3548)$ did not look at graft patency. ${ }^{21-23}$ Consequently, because graft occlusion uncommonly causes clinical events, the observational studies are unlikely to show a difference in clinical outcomes even if one of the groups had a higher incidence of graft closure due to competitive flow. Measurement of clinical events is a poor indicator of graft occlusion due to competitive flow. A recent observational study comparing outcomes from 2 different institutions with bilateral ITA Y $(\mathrm{n}=771)$ configuration at one institution and bilateral ITA in situ $(\mathrm{n}=436)$ at the other provided a large cohort for analysis and showed a survival benefit for the bilateral ITA Y configuration at a mean follow-up of 7 years. ${ }^{24}$
However, a recent meta-analysis of the studies comparing in situ with Y graft ITA configurations showed no significant difference in clinical outcomes. ${ }^{25}$

\section{Competitive Flow and Bypass Grafts}

Although saphenous vein graft patency rates are more resistant to the effects of competitive flow, they are also associated with accelerated native coronary artery disease in comparison with arterial grafts. ${ }^{26,27}$

Analyses of symptom-driven late angiography from the Cleveland Clinic ${ }^{26}(\mathrm{n}=4333)$ and Westmead Hospital ${ }^{28}$ $(n=296)$ have suggested a near linear relationship between the odds ratio of ITA graft occlusion and the severity of the native vessel stenosis between $50 \%$ and $100 \%$ as seen at preoperative angiography. At the Cleveland Clinic, the grafts were predominantly in situ individual ITA grafts, and at Westmead Hospital they were entirely bilateral ITA Y grafts from the left ITA. Despite this, the relative risk of graft occlusion due to competitive flow was similar. There is no threshold in this range $(\geq 50 \%$ stenosis $)$ at which the patency of ITA grafts substantially decreases in either group. The risk of occlusion of an ITA graft to a coronary artery with a $50 \%$ stenosis is approximately 4 times the risk of occlusion to an equivalent vessel with a proximal occlusion (100\%). Because the risk of an ITA graft occlusion to a completely occluded coronary artery is low, even a 4-fold increase is still low, and the majority of ITA grafts remain patent. ${ }^{26,28}$ The graft patency rate and patient survival at 10 years exceed that of vein grafts for all such coronary vessels except grafts to the right coronary artery. ${ }^{17,26}$

In summary, there is no evidence that any configuration of bilateral ITAs is better than another for equivalent myocardial territories grafted, and because the Y-graft configuration permits a greater number of distal anastomoses, this provides a wider ITA grafted myocardial territory with a reduced requirement for subsequent revascularization and a possible small survival benefit.

\section{Angiographic Assessment of Competitive Flow}

For assessment of asymptomatic graft closure rates, midterm elective angiography or computed tomography angiography is required. This is uncommon and usually restricted to rigorously conducted trials. Early elective angiography is routinely performed in many Japanese centers, and the group from the National Cardiovascular Centre in Osaka (Nakajima and colleagues ${ }^{29}$ ) has published numerous analyses of the findings of competitive flow at early routine angiography and the incidence of graft failure at subsequent symptom-driven angiography. Using composite arterial graft configurations and multiple sequential anastomoses were predictors of the finding of competitive flow at early angiography, and the finding of competitive flow predicted subsequent graft occlusion. However, 


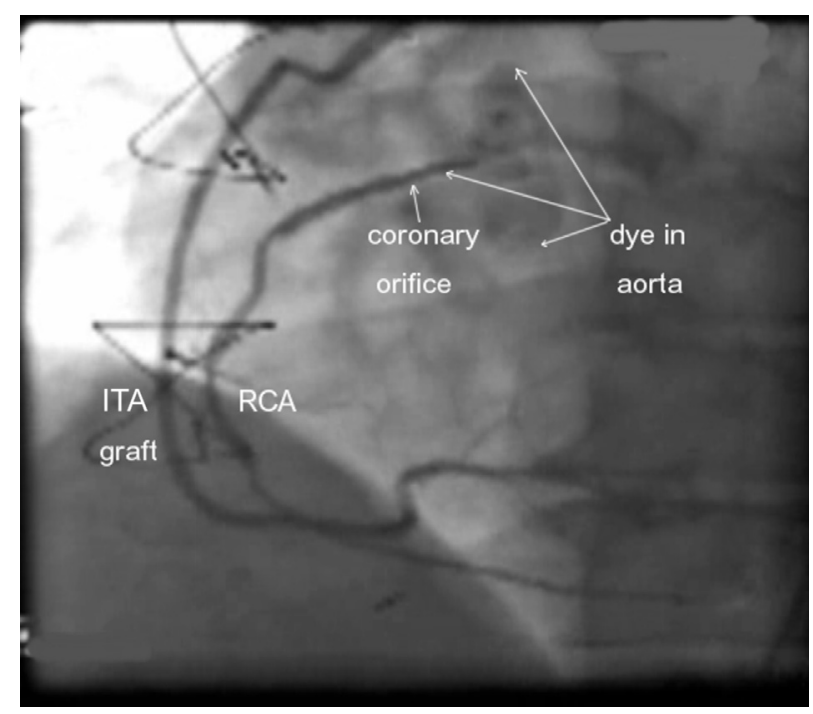

FIGURE 1. Dye injection into a 12-year-old aortocoronary ITA graft with minimal back flush from the ITA orifice but with dye flowing freely back up the right coronary artery with the jet hitting the opposite side of the aortic wall. ITA, Internal thoracic artery; $R C A$, right coronary artery.

composite arterial grafting was not a predictor of graft occlusion. ${ }^{29}$ Graft flow was graded as $\mathrm{A}=$ antegrade, $\mathrm{B}=$ balanced, $\mathrm{C}=$ competitive, and $\mathrm{O}=$ graft occlusion.
The finding of competitive flow $(\mathrm{B}+\mathrm{C}+\mathrm{O})$ was used as a binary variable. It has also been graded as $0=$ occlusion, $1=$ dominant flow from native coronary, $2=$ balanced flow between graft and coronary, $3=$ dominant graft flow, and $4=$ graft flow only. Grades 0 to 2 have been labeled "nonfunctional grafts," 30 a term that is misleading. Coronary angiography is performed at rest, and the effects of exercise on graft and coronary flow interaction in the presence of competitive flow have not been studied in detail. Although a negative FFR might suggest that the flow competition will persist during exercise, the probability is that the majority of these arterial grafts will remain patent.

More important, the graft angiography technique tends to be standardized regardless of the nature of the graft. Therefore, a high-flow graft will receive the same pressure and volume of dye injection as a low-flow graft. The dye in a high-flow graft with multiple coronary anastomoses will be diluted by the higher graft flow and have more difficulty opacifying all coronary anastomoses. This was confirmed by Nakajima and colleagues, ${ }^{31}$ who found that high-flow grafts (composite grafts and single grafts with multiple anastomoses) predicted the finding of competitive flow, but only low-flow grafts (single grafts or terminal segments of sequential grafts, particularly to the right coronary

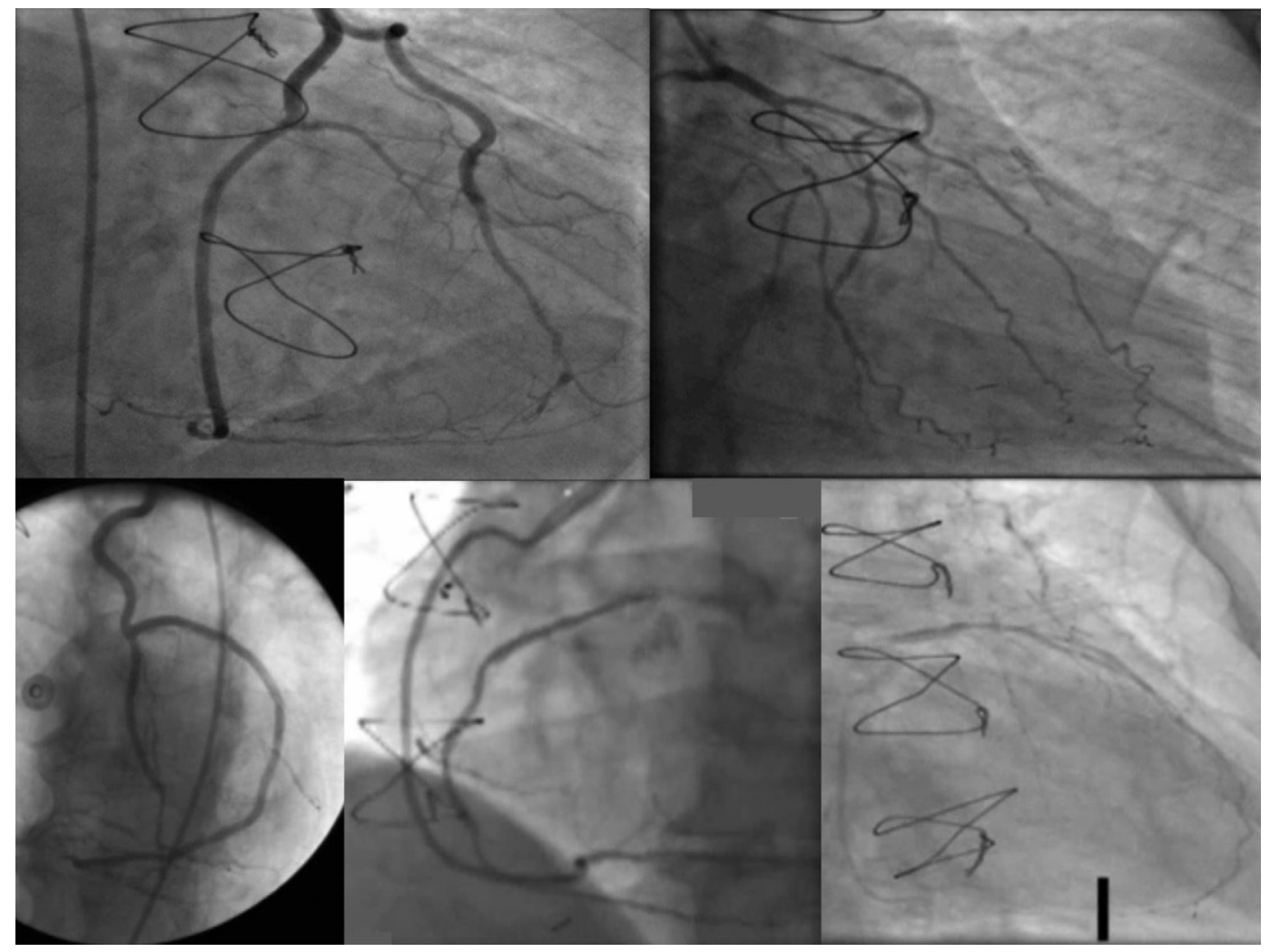

VIDEO 1. The angiogram in Figure 1 is displayed along with 7 examples of composite and sequential ITA grafts showing various effects of competitive flow with interpretation of the findings (6 minutes, 30 seconds). Video available at: http://www.jtcvsonline.org/article/S0022-5223(17)31149-2/addons. 
system) predicted graft occlusion in association with competitive flow. High-flow arterial grafts also have greater internal diameters such that there is less resistance to backflush of dye with resultant dissipation of both dye volume and pressure. Figure 1 and Video 1 show the effects of deep engagement of a 12-year-old single ITA graft. With little back-flush of dye, the full pressure and volume of the injectate was transmitted down the graft and back up the coronary artery into the aorta. Pevni and colleagues ${ }^{32}$ have reported grafts where the anastomoses have been opacified only by increasing the pressure and volume of the injectate above the standard amount. The finding of competitive flow at early postoperative angiography alone is an unreliable predictor of subsequent clinical events.

\section{CONCLUSIONS}

FFR has proven benefit in guiding PCI. There is no evidence that FFR improves the clinical outcomes of coronary surgery, although the greater accuracy in assessing coronary stenoses is appealing. The improved accuracy provided by the addition of FFR might allow downgrading of the visual severity of coronary disease from prognostically significant, but this is an assumption and not supported by current evidence. There is no evidence that any configuration of bilateral ITAs is better than another in any respect for equivalent myocardial territories grafted, including the effects of competitive flow. The presence of competitive flow in moderately stenotic branches of the left coronary system does not reduce ITA graft patency below that of vein grafts. We recommend the following: Clinicians who perform FFR-guided coronary bypass surgery should prospectively record all relevant data (including data on patients downgraded to PCI) required for publication of observational and comparative studies. Depending on the findings of the FUnctional Testing Underlying Coronary REvascularization trial, a randomized trial of FFR-guided versus angiography-guided coronary grafting of moderate stenoses only, without management downgrading, may be useful. Such a trial should be sufficiently powered to allow subset analyses of high runoff and low runoff coronary arteries, different myocardial territories, and sequential or end-toside anastomoses.

\section{Conflict of Interest Statement}

Authors have nothing to disclose with regard to commercial support.

\footnotetext{
References

1. Tonino PA, De Bruyne B, Pijls NH, Siebert U, Ikeno F, van't Veer M, et al. Fractional flow reserve versus angiography for guiding percutaneous coronary intervention. N Engl J Med. 2009;360:213-24.

2. Pijls NH, De Bruyne B, Peels K, Van Der Voort PH, Bonnier HJ, Bartunek J, et al. Measurement of fractional flow reserve to assess the functional severity of coronary-artery stenoses. N Engl J Med. 1996;334:1703-8.
}

3. De Bruyne B, Hersbach F, Pijls NH, Bartunek J, Bech JW, Heyndrickx GR, et al. Abnormal epicardial coronary resistance in patients with diffuse atherosclerosis but "Normal" coronary angiography. Circulation. 2001;104:2401-6.

4. Pijls NH, van Schaardenburgh P, Manoharan G, Boersma E, Bech JW, van't Veer $\mathrm{M}$, et al. Percutaneous coronary intervention of functionally nonsignificant stenosis: 5-year follow-up of the DEFER Study. J Am Coll Cardiol. 2007;49: 2105-11.

5. van Nunen LX, Zimmermann FM, Tonino PA, Barbato E, Baumbach A, Engstrøm T, et al. Fractional flow reserve versus angiography for guidance of PCI in patients with multivessel coronary artery disease (FAME): 5-year follow-up of a randomised controlled trial. Lancet. 2015;386:1853-60.

6. Rioufol G, Mewton N, Rabilloud M, Vaz B, Roubille F, Perret T, et al. The FUnctional Testing Underlying Coronary REvascularization (FUTURE) study: a "real world" comparison of fractional flow reserve-guided management versus conventional management in multi vessel coronary artery disease patients. Presented at: American Heart Association Scientific Sessions; November 14, 2016; New Orleans, LA. Available at: http://www.abstractsonline.com/pp8/ \#!/4096/presentation/58258. Accessed June 18, 2017.

7. Botman KJ, Pijls NH, Bech JW, Aarnoudse W, Peels K, van Straten B, et al. Percutaneous coronary intervention or bypass surgery in multivessel disease? A tailored approach based on coronary pressure measurement. Catheter Cardiovasc Interv. 2004;63:184-91.

8. Toth G, De Bruyne B, Casselman F, De Vroey F, Pyxaras S, Di Serafino L, et al. Fractional flow reserve-guided versus angiography-guided coronary artery bypass graft surgery. Circulation. 2013;128:1405-11.

9. Mohr FW, Morice MC, Kappetein AP, Feldman TE, Ståhle E, Colombo A, et al. Coronary artery bypass graft surgery versus percutaneous coronary intervention in patients with three-vessel disease and left main coronary disease: 5year follow-up of the randomised, clinical SYNTAX trial. Lancet. 2013;381: 629-38.

10. Alexander JH, Smith PK. Coronary-artery bypass grafting. N Engl J Med. 2016; 374:1954-64.

11. Passamani E, Davis KB, Gillespie MJ, Killip T. A randomized trial of coronary artery bypass surgery. Survival of patients with a low ejection fraction. $N$ Engl J Med. 1985;312:1665-71.

12. Yusuf S, Zucker D, Peduzzi P, Fisher LD, Takaro T, Kennedy JW, et al. Effect of coronary artery bypass graft surgery on survival: overview of 10-year results from randomised trials by the Coronary Artery Bypass Graft Surgery Trialists Collaboration. Lancet. 1994;344:563-70.

13. Mack M, Baumgarten H, Lytle B. Why surgery won the SYNTAX trial and why it matters. J Thorac Cardiovasc Surg. 2016;152:1237-40.

14. Wu C, Camacho FT, Zhao S, Wechsler AS, Culliford AT, Lahey SJ, et al. Longterm mortality of coronary artery bypass graft surgery and stenting with drugeluting stents. Ann Thorac Surg. 2013;95:1297-305.

15. Smith PK, Califf RM, Tuttle RH, Shaw LK, Lee KL, Delong ER, et al. Selection of surgical or percutaneous coronary intervention provides differential longevity benefit. Ann Thorac Surg. 2006;82:1420-8.

16. Jones EL, Weintraub WS. The importance of completeness of revascularization during long-term follow-up after coronary artery operations. J Thorac Cardiovasc Surg. 1996;112:227-37.

17. Sabik JF III, Olivares G, Raza S, Lytle BW, Houghtaling PL, Blackstone EH. Does grafting coronary arteries with only moderate stenosis affect long-term mortality? J Thorac Cardiovasc Surg. 2016;151:806-11.

18. Tatoulis J, Buxton BF, Fuller JA. Patencies of 2127 arterial to coronary conduits over 15 years. Ann Thorac Surg. 2004;77:93-101.

19. Glineur D, Hanet C, Poncelet A, D'hoore W, Funken JC, Rubay J, et al. Comparison of bilateral internal thoracic artery revascularization using in situ or Y graft configurations: a prospective randomized clinical, functional, and angiographic midterm evaluation. Circulation. 2008;118(14 Suppl): S216-21.

20. Glineur D, Boodhwani M, Hanet C, de Kerchove L, Navarra E, Astarci P, et al. Bilateral internal thoracic artery configuration for coronary artery bypass surgery: a prospective randomized trial. Circ Cardiovasc Interv. 2016;9:e003518.

21. Lev-Ran O, Paz Y, Pevni D, Kramer A, Shapira I, Locker C, et al. Bilateral internal thoracic artery grafting: midterm results of composite versus in situ crossover graft. Ann Thorac Surg. 2002;74:704-10.

22. Hwang HY, Kim JS, Cho KR, Kim KB. Bilateral internal thoracic artery in situ versus y-composite graftings: five-year angiographic patency and long-term clinical outcomes. Ann Thorac Surg. 2011;92:579-85. 
23. Di Mauro M, Iacò AL, Allam A, Awadi MO, Osman AA, Clemente D, et al. Bilateral internal mammary artery grafting: in situ versus Y-graft. Similar 20year outcome. Eur J Cardiothorac Surg. 2016;50:729-34.

24. Glineur D, Etienne PY, Kuschner CE, Shaw RE, Ferrari G, Rioux N, et al. Bilateral internal mammary artery $\mathrm{Y}$ construct with multiple sequential grafting improves survival compared to bilateral internal mammary artery with additional vein grafts: 10-year experience at 2 different institutions $\dagger$. Eur J Cardiothorac Surg. 2017;51:368-75.

25. Yanagawa B, Verma S, Jüni P, Tam DY, Mazine A, Puskas JD, et al. A systematic review and meta-analysis of in situ versus composite bilateral internal thoracic artery grafting. J Thorac Cardiovasc Surg. 2017;153:1108-16.

26. Sabik JF III, Lytle BW, Blackstone EH, Houghtaling PL, Cosgrove DM. Comparison of saphenous vein and internal thoracic artery graft patency by coronary system. Ann Thorac Surg. 2005;79:544-51.

27. Dimitrova KR, Hoffman DM, Geller CM, Dincheva G, Ko W, Tranbaugh RF. Arterial grafts protect the native coronary vessels from atherosclerotic disease progression. Ann Thorac Surg. 2012;94:475-81.
28. Robinson BM, Paterson HS, Naidoo R, Dhurandhar V, Denniss AR. Bilateral in ternal thoracic artery composite Y grafts: analysis of 464 angiograms in 296 patients. Ann Thorac Surg. 2016;101:974-80.

29. Nakajima H, Kobayashi J, Tagusari O, Niwaya K, Funatsu T, Kawamura A, et al Angiographic flow grading and graft arrangement of arterial conduits. J Thorac Cardiovasc Surg. 2006;132:1023-9.

30. Glineur D, Hanet C, D'hoore W, Poncelet A, De Kerchove L, Etienne PY, et al. Causes of non-functioning right internal mammary used in a Y-graft configuration: insight from a 6-month systematic angiographic trial. Eur J Cardiothorac Surg. 2009;36:129-35.

31. Nakajima H, Kobayashi J, Toda K, Fujita T, Shimahara Y, Kasahara Y, et al Angiographic evaluation of flow distribution in sequential and composite arterial grafts for three vessel disease. Eur J Cardiothorac Surg. 2012;41: 763-8.

32. Pevni D, Hertz I, Medalion B, Kramer A, Paz Y, Uretzky G, et al. Angiographic evidence for reduced graft patency due to competitive flow in composite arteria T-grafts. J Thorac Cardiovasc Surg. 2007;133:1220-5. 